\title{
Paediatric Ocular Injuries Associated with Ghanaian Recreational Activities in the Ashaiman Municipality, Ghana
} \author{
Agyemang-Mireku² and Kwabena Gyabaah Yeboah ${ }^{2}$ \\ ${ }^{1}$ Hohoe Municipal Hospital, Ghana \\ ${ }^{2}$ Department of Optometry and Visual Science, Kwame Nkrumah University of Science and Technology, Ghana \\ ${ }^{3}$ Department of Epidemiology and Biostatistics, University of Health and Allied Sciences, Ghana
}

Paula Sefadzi Nkrumah Gatsey ${ }^{1}$, Michel Pascal Tchiakpe ${ }^{2}$, David Ben Kumah' ${ }^{2 *}$ Mavis Pearl Kwabla ${ }^{3}$, Felix

Submission: April 11, 2017; Published: June 13, 2017

*Corresponding author: David Ben Kumah, Department of Optometry and Visual Science, Kwame Nkrumah University of Science and Technology, Kumasi, Ghana, Email: ben56kay@gmail.com

Abstract

Background: Recreational activities are essential part of a child's development. Unfortunately, such activities may expose the child to eye injuries which contribute to blindness in children. The study assessed the ocular injuries which occur in children who engage in Ghanaian recreational activities and the health seeking behaviours of parents/guardians when a child had an ocular injury.

Methods: In this cross-sectional survey, records in the Tema General Hospital were reviewed. Questionnaires administered to children and parents/caretakers, and interviews of healthcare professionals served as data sources for the study.

Results: Over $70 \%$ of paediatric ocular injuries were found to occur at home. Child abuse (42.2\%), thermal injury (36.5\%) and chemical splash (22.2\%) were the main causes of ocular injuries as reported by the sampled children. According to 11 parents and 201 children who responded to questions on post-injury seeking behaviour, $39.4 \%$ did not visit the clinic due to financial constraints, $23.1 \%$ took no action, only $19.7 \%$ visited the hospital with $8.7 \%$ resorting to self-medication. Paediatric ocular injury occurred most frequently during football games (36.1\%). Children aged 6-10 years were found to be most prone to eye injury as $57.1 \%$ of the cases were among this age group. Males were found to be more likely to sustain ocular injuries compared to females.

Conclusion: Over $80 \%$ of ocular injuries were due to games children played with the rest being open fire and chemical burns. Home management of ocular injury was common among respondents with the reason being financial constraints.

Keywords: Ocular injuries; Traumatic conjunctivitis; Paediatric; Recreational activities

\section{Introduction}

An ocular injury is a physical damage to the eye, including all its structures-eyelids, cornea, anterior chamber, lens, retina, extra ocular muscles and nerves [1,2]. Sports form a very important aspect of children's life. Children usually engage in recreational activities, which help in their development as well as serve as a form of exercise. These activities, however, can cause minor as well as catastrophic injuries to their eyes [3]. The risk of children easily getting injured in the eye is high because they are unable to avoid hazards. Most of these hazards are intrinsic in the kind of games children play [4]. Blindness in childhood may interfere with the normal development and education of a child. Existing data on magnitude and distribution of ocular trauma in developing countries is very scarce and are difficult to interpret; reporting is extremely poor especially because of the completely different settings of the occurrence of ocular trauma [5].

There are about 1.5 million blind children, and this number appears to be increasing. Nearly 500,000 children became blind every year (that is, one child gets blind every minute) and about half of them die within 1 or 2 years of becoming blind $[6,7]$. Approximately one-third of the total economic cost of blindness was thought to be due to childhood blindness [6]. Children must therefore be protected from activities that cause harm to the eye. Ocular injuries range from minor ones such as getting sand 
into the eye to the catastrophic ones like cutting the cornea with metals as may Occur in most of Ghanaian indigenous games. The control of blindness in children is considered a high priority within the World Health Organizations vision 2020-The Right to Sight programme [8]. Many of the causes of blindness in children are either preventable or treatable. The major causes of blindness in children vary widely from region to region, being largely determined by socioeconomic development, and the availability of primary health care as well as eye care services. In low-income countries with high under-5 mortality rates, the prevalence of blindness in children was as high as 1.5 per 1000 children, while in high-income countries with low under-5 mortality rates, the prevalence was around 0.3 per 1000 children. Using this correlation to estimate the prevalence of blindness in children, the number of blind children in the world was about 1.4 million at the time. A quarter less of the world's blind children live in the poorest regions of Africa and Asia [9]. In developing countries, the causes of childhood blindness had not been widely studied. To plan effective intervention and prevention programmes, an awareness of the causes of blindness and the magnitude of the problem was crucial [10].

Incidence rates for hospitalized ocular injury in the developed world was found to be 8 per 100,000 for Scotland, 13 per 100,000 in the United States and 33 per 100,000 population for Papua New Guinea, which is not a developed world [11-13]. The situation was worse in developing countries where the problem was compounded by general lack of access to preventive health care at all levels [14]. The National Eye Institute (NEI) in 2008, indicated that eye injuries were the leading cause of blindness in school-aged children. Another organization, Prevent Blindness America, also reported that sports-related eye injuries were the leading cause of blindness in school-age children, even though most could be prevented with proper eye protection [3]. Many children who have ocular injury do not get the right medical care. In the area of study for example, proper and affordable health care is not easily accessible by people living there, as gathered from a pilot study. This study assessed the ocular injuries that occur among children during Ghanaian local sports as well as the ocular health seeking behaviour of parents and guardians for their injured children in parts of the Ashaiman Municipality of Ghana.

\section{Materials and Methods}

\section{Study design and Sampling}

The study was a descriptive cross-sectional survey conducted at the Tema General hospital. The study population included children, their parents/caretakers in the Ashaiman Municipality. To obtain clinical information, health professionals' knowledge in eye injuries were solicited through key informant interviews. Ten public basic schools were randomly selected from the seventeen public schools that existed at the time of the study. Simple random sampling and purposive sampling were used to select the schools visited as well as convenient sampling methods to obtain the study samples from some of the parents studied.

\section{Data collection}

The data collected included secondary data on eye injuries from the Tema General Hospital Records. Primary data were obtained through key informant interviews and administration of questionnaires to children, parents/caretakers. Questionnaires were administered to 201 children and 11 parents. Seven (7) doctors/paramedics were also interviewed.

\section{Data analysis}

Both quantitative and qualitative data were gathered and analysed. Data was entered into Microsoft Excel (2016; Microsoft, Redmond, WA) for analysis. The results were presented in graphs and tables. Descriptive statistics was employed.

\section{Ethical consideration}

Informed consent was obtained from the parents/ caretakers of the sampled children and all other participants after the rationale of study was explained to them. Permission was also obtained from the authorities of Tema General Hospital, Municipal Director of Education and headmasters of selected schools. The study complied with the principles of the Declaration of Helsinki [15].

\section{Results}

The study included a total of 201 children in basic schools between ages $0-15$ years and 11 parents as well as 7 doctors/ paramedics.

\section{Socio-demographic Characteristics of Children Respondents}

Of the total of 201 children interviewed, majority (57\%) were between ages 6-10 years followed by 0-5 years (29\%) and 11-15 years (14\%). Males were in the majority 102 (51\%). The children were all school children with $86 \%$ of them in the primary school while the remaining $14 \%$ were in junior high school.

\section{Causes of Ocular Injuries Reported at Health Facilities}

The study found majority $73 \%$ of ocular injuries to be home based with $27 \%$ school based (Figure 1). Of the $27 \%$ of ocular injuries occurring in schools, the causes as reported at health facilities were due to trauma from sticks during games which recorded $86 \%$ and open fire/chemical burns which constituted $14 \%$ of cases. Other causes of ocular injury reported by the children sampled included child abuse, 80 (42.3\%) thermal injury, 67 (35.5\%) and chemical splash, 42 (22.2\%) depicts the types of paediatric eye injuries sustained as a result of sports. Traumatic conjunctivitis was the most frequent injury, recording $28 \%$, while endophthalmitis and blow out fracture were the least frequent injuries with 3\% each. Table 2 outlines games played by children in the Ashaiman Municipal Assembly 
which could cause injury. Football was the most frequently played game by children with $36 \%$ of the children engaged in the game, whereas the least patronized sport was wrestling and fist fighting, recording $3.7 \%$. Stones were found to cause most ocular injuries according to $40.3 \%$ of children that were questioned, while $3.5 \%$ of the children respondents stated sand caused injury; this represented the least frequent object causing ocular injury. Further details are shown in (Figure 2 \& Table 3) depicts the action taken by injured children and their parents after ocular injury had occurred. Only $19.7 \%$ visit the hospital in the event of ocular injuries. About $40 \%$ did not go to the eye clinic due to financial constraints whilst $1.4 \%$ of the children did not tell their parents because of fear of punishment. Though this represented the least, it is quiet disturbing. The gender distribution of children who claimed to have ocular injuries showed that males $56(56.6 \%)$ were more injured than females $43(43.4 \%)$. However, from the perspective of health practitioners, $70 \%$ of them said males had more ocular injuries than the females. A few (29\%) on the other hand claimed both males and females were equally injured. From the perspective of parents, $91 \%$ of them stated that males were likely to get injured more than females. However, $9 \%$ of the parents claimed that the females were more prone to ocular injury than males $[16,17]$.

Table 1: Reported Paediatric Ocular Cases as a Result of Recreational Activities, Tema General Hospital, June - August 2009.

\begin{tabular}{|c|c|}
\hline Type of Injury & Number of Cases (\%) \\
\hline Traumatic conjunctivitis & $10(27.8)$ \\
\hline Corneal foreign body & $3(8.3)$ \\
\hline Blephero-conjunctivitis & $3(8.3)$ \\
\hline Traumatic cataract & $5(13.9)$ \\
\hline Corneal laceration & $2(5.6)$ \\
\hline Endophthalmitis & $1(2.8)$ \\
\hline Blow out fracture & $1(2.8)$ \\
\hline Tarsal foreign body & $2(5.6)$ \\
\hline Retinal detachment & $2(5.6)$ \\
\hline Sub-conjunctival haemorrhage & $2(5.6)$ \\
\hline Corneal ulcer & $5(13.9)$ \\
\hline Total & $\mathbf{3 6}(\mathbf{1 0 0})$ \\
\hline
\end{tabular}

Source: Tema General Hospital, Between June and August 2009.

Table 2: Types of Games Causing Paediatric Ocular Injury.

\begin{tabular}{|c|c|}
\hline Type of Recreation & Number of Children (\%) \\
\hline 'Pilolo' [16,17] & $71(21.9)$ \\
\hline 'Ampe' [16] & $60(18.5)$ \\
\hline 'Chaskele' [17] & $19(5.9)$ \\
\hline 'Stay' [17] & $25(7.7)$ \\
\hline 'Police and thief' & $20(6.2)$ \\
\hline Wrestling and fist fighting & $12(3.7)$ \\
\hline Football & $117(36.1)$ \\
\hline Total & $\mathbf{3 2 4}(\mathbf{1 0 0})$ \\
\hline
\end{tabular}

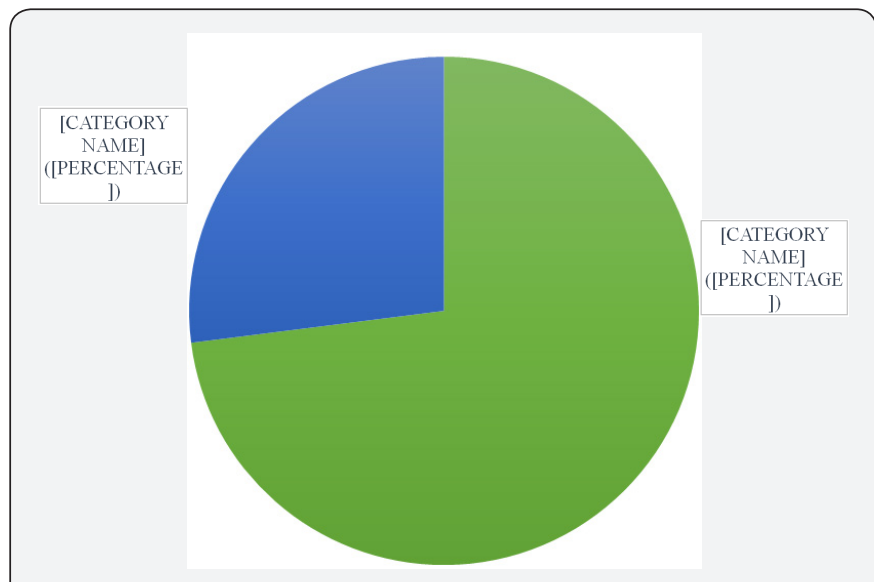

Figure 1: Causes of ocular Injuries Reported at Health Facilities.

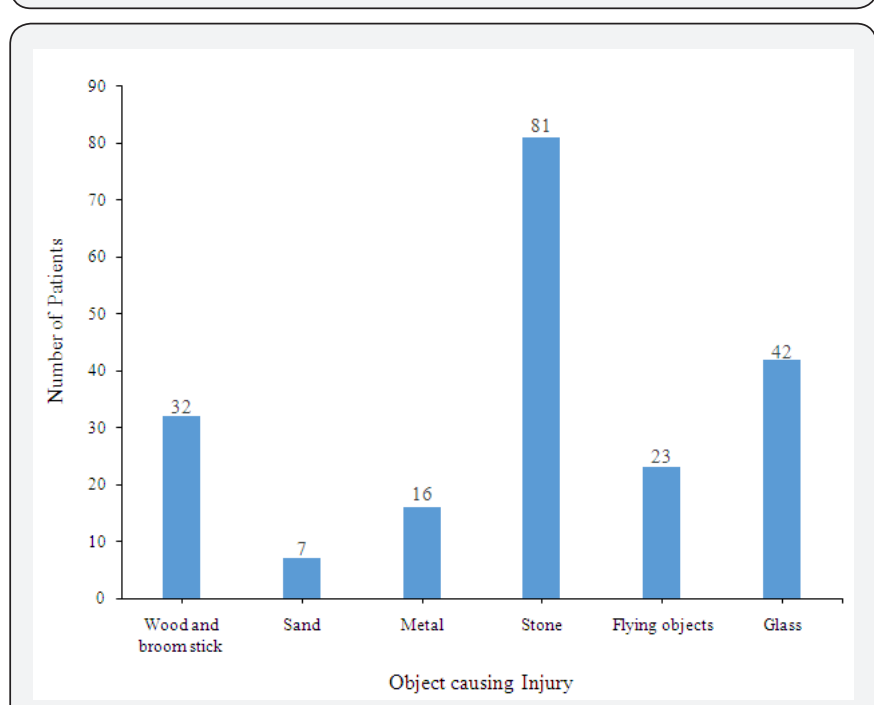

Figure 2: Objects Causing Paediatric Ocular Injury.

Table 3: Management of Ocular Injuries by Parents and Injured Children after Injury.

\begin{tabular}{|c|c|}
\hline $\begin{array}{c}\text { Do not tell parents because of } \\
\text { fear of punishment }\end{array}$ & No. of Patients (\%) \\
\hline $\begin{array}{c}\text { Do not go to the clinic due to } \\
\text { financial constraints }\end{array}$ & $82(39.4)$ \\
\hline Not painful hence no action & $48(23.1)$ \\
\hline Visit the pharmacy & $16(7.7)$ \\
\hline Self-medicate & $18(8.7)$ \\
\hline Visit the hospital & $41(19.7)$ \\
\hline Total & $\mathbf{2 0 8}(\mathbf{1 0 0})$ \\
\hline
\end{tabular}

\section{Discussion}

Sports or recreational activities are an essential part of a child's development. Unfortunately, such activities may expose the child to eye injuries which contribute to blindness in children. The study assessed the ocular injuries which occur in children who engage in Ghanaian local childhood recreational activities 
and the health seeking behaviours of parents/guardians when a child had an ocular injury. A total of 201 primary and Junior high school children were included in the study with majority (57\%) being between ages 6-10 years. This is expected since majority $(86 \%)$ of the children were in primary school compared to those in Junior high school. Males were in the majority 102 (51\%). Similarly, ocular trauma was found to occur mostly in children aged 0-15 years and with a male preponderance of 78.8\% [1]. A study by Kanoff et al. [18] also found as high as $98 \%$ of males have eye injuries compared to females. Again another study also found $56.2 \%$ of eye injuries occurring in males with the majority being in age group 0-14 years [2]. The study found majority $(73 \%)$ of ocular injuries to occur in homes compared to schools. There is therefore the need to intensify eye health education in homes. The causes of ocular injury as reported by the health facilities included trauma from sticks during games (86\%) and open fire/chemical burns which constituted 14\% of cases. This calls for concern since games play an important role in the lives of children. Paediatric ocular injury was found to occur most frequently during the games of football (36.1\%), 'pilolo' (21.9\%) and 'ampe' (18.5\%). Wrestling and fist-fighting had the least injury cases (3.7\%). This was similar to a study on holistic face training enhances face processing in developmental prosopagnosia, reported that sports-related eye injuries were the leading cause of blindness in school-age children [19].

Causal objects of ocular injuries were stone $(40.3 \%)$, glass (20.9\%), wood/broom sticks (15.1\%), flying debris (11.4\%) and sand $(3.5 \%)$. It is therefore recommended that protective gear should be made available for children when they are playing. In assessing the types of paediatric eye injuries sustained as a result of sports, the study found traumatic conjunctivitis to be the most frequently occurring injury, recording $28 \%$ while endophthalmitis and blow out fracture were the least frequent injuries with $3 \%$ each. On action taken by injured children and their parents after ocular injury had occurred, the study revealed that only $19.7 \%$ visit the hospital in the event of ocular injuries. About $40 \%$ did not go to the eye clinic due to financial constraints whilst $1.4 \%$ of the children did not tell their parents because of fear of punishment. Though this represented the least, it is quiet disturbing.

\section{Conclusion}

As high as $86 \%$ of paediatric ocular injury cases reported to the Tema General Hospital were due to games children played. Home management of ocular injury was common among respondent. Most parents (39.4\%) did not seek medical care because of financial constraints. The most common type of ocular injury associated with local games was traumatic conjunctivitis, which recorded $28 \%$. Based on the information obtained from the study, health education about ocular health must be intensified to draw attention of parents and children on the need to protect the child's eye.

\section{Conflict of Interest}

The authors of this research article declare that they have no conflict of interests regarding the publication of this manuscript.

\section{References}

1. Soylu M, Sizmaz S, Cayli S (2010) Eye injury (ocular trauma) in southern Turkey: epidemiology, ocular survival, and visual outcome. International Ophthalmology 30(2): 143-148.

2. Cao H, Li L, Zhang M (2012) Epidemiology of patients hospitalized for ocular trauma in the Chaoshan region of China, 2001-2010. PloS One 7(10): e48377.

3. Koutures CG, Gregory A J (2010) Injuries in youth soccer. Pediatrics 125(2): 410-414.

4. Schwebel DC, Speltz M L, Jones K, Bardina P (2002) Unintentional injury in preschool boys with and without early onset of disruptive behavior. Journal of Pediatric Psychology 27(8): 727-737.

5. Girkin CA, Gwin Mc G, Long C, Morris R, Kuhn F (2005) Glaucoma after ocular contusion: a cohort study of the United States Eye Injury Registry. Journal of Glaucoma 14(6): 470-473.

6. Thylefors B, Negrel AD, Pararajasegaram R, Dadzie KY (1995) Global data on blindness. Bulletin of the World Health Organization 73(1): 115-121.

7. Brophy M, Sinclair SA, Hostetler SG, Xiang H (2006) Pediatric eye injury-related hospitalizations in the United States. Pediatrics 117(6): e1263-e1271.

8. Pizzarello L, Abiose A, Ffytche T, Duerksen R, Thulasiraj R, et al. (2004) VISION 2020: The Right to Sight: a global initiative to eliminate avoidable blindness. Archives of Ophthalmology 122(4): 615-620.

9. Whitcher JP, Srinivasan M, Upadhyay MP (2001) Corneal blindness: a global perspective. Bulletin of the World Health Organization 79(3): 214-221.

10. Resnikoff S, Pascolini D, Etya'ale D, Kocur I, Pararajasegaram R, et al. (2004) Global data on visual impairment in the year 2002. Bulletin of the World Health Organization 82(11): 844-851.

11. Desai P, MacEwen CJ, Baines P, Minassia DC (1996) Incidence of cases of ocular trauma admitted to hospital and incidence of blinding outcome. British Journal of Ophthalmology 80(7): 592-596.

12. Martínez RJ (1998) El herido ocular en lascontiendasbélicas. Revista Cubana de Medicina Militar 27(2): 124-132.

13. Verma N, Verma A, Jacob G, Demok S (1997) Profile of ocular trauma in Papua New Guinea. Australian and New Zealand Journal of Ophthalmology 25(2): 151-155.

14. Gyasi ME, Amoaku WMK, Adjuik MA (2007) Epidemiology of hospitalized ocular injuries in the upper East region of Ghana. Ghana Med J 41(4): 171-175.

15. World Medical Association (2001) World Medical Association Declaration of Helsinki. Ethical Principles for Medical Research Involving Human Subjects. Bull World Health Org 79(4): 373-374.

16. Nieboer G. (1995). Kids Games. [Updated 8 October 2011].

17. Boakye K. (2016). 8 spectacular games you never played as a Ghanaian kid because you're totally dadabee.

18. Kanoff J M, Turalba AV, Andreoli MT, Andreoli CM (2010) Characteristics and outcomes of work-related open globe injuries. American Journal of Ophthalmology 150(2): 265-269.

19. DeGutis J, Cohan S, Nakayama K (2014) Holistic face training enhances face processing in developmental prosopagnosia. Brain 062. 
This work is licensed under Creative Commons Attribution 4.0 License DOI:10.19080/JOJ0.2017.03.555615
Your next submission with Juniper Publishers will reach you the below assets

- Quality Editorial service

- Swift Peer Review

- Reprints availability

- E-prints Service

- Manuscript Podcast for convenient understanding

- Global attainment for your research

- Manuscript accessibility in different formats

( Pdf, E-pub, Full Text, Audio)

- Unceasing customer service

Track the below URL for one-step submission https://juniperpublishers.com/online-submission.php 